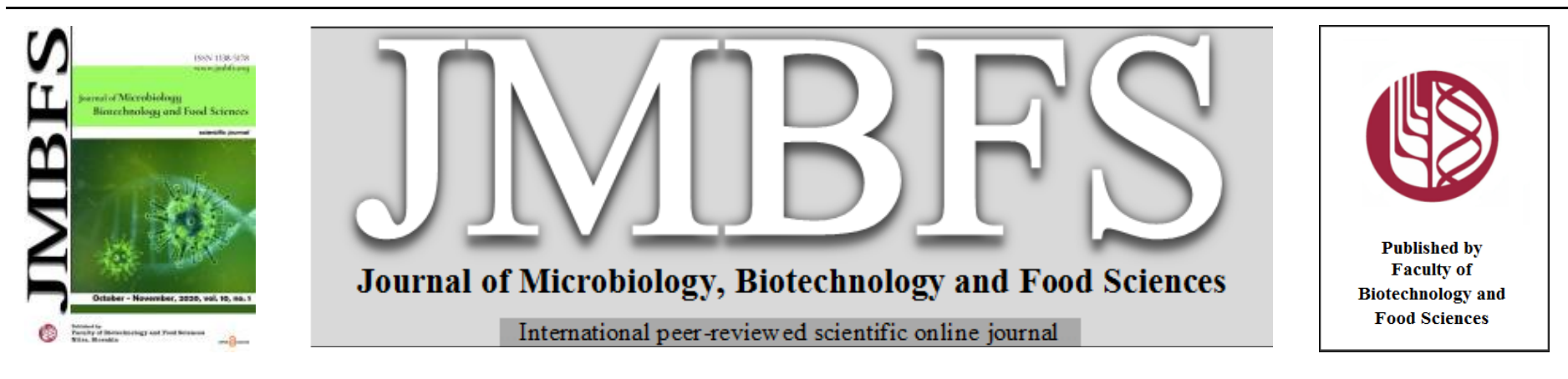

\title{
WASTEWATER PURIFICATION FROM ANTIBIOTICS WITH SIMULTANIOUS BIOGAS PRODUCTION
}

\author{
Natalia Golub ${ }^{1}$, Zhu Ying ${ }^{2}$, Malvina Shinkarchuk ${ }^{* 1}$, Olexandr Kozlovets ${ }^{1}$, Igor Levtun ${ }^{1}$, Shan Ranra ${ }^{2}$ \\ Address(es): PhD student Malvina Shinkarchuk \\ ${ }^{1}$ Igor Sikorsky Kyiv Polytechnic Institute, Department of ecobiotechnology and bioenergy, Peremohy av., 37, 03056, Kyiv, Ukraine, $+38(068) 0029514$. \\ ${ }^{2}$ Advanced Materials Institute, Shandong Academy of Sciences, 250014, Jinan, China.
}

*Corresponding author: malvina.schinkarchuk@gmail.com

doi: 10.15414/jmbfs.2020.10.2.170-175

\section{ARTICLE INFO}

Received 10.12. 2019

Revised 2. 6. 2020

Accepted 3. 6. 2020

Published 1. 10. 2020

Regular article

OPEN OACCESS

\section{ABSTRACT}

The possibility of biogas obtaining in a pharmaceutical plant anaerobic wastewater treatment process, which contains antibiotics of different classes (tetracycline, norfloxacin, cephalosporin, penicillin) has been studied. The enzymatic process was conducted in the mesophilic regime $\left(37 \pm 1^{\circ} \mathrm{C}\right)$ using free-floating and granulated anaerobic sludge. As granulation centers, talc-based sorbents were used. It was shown that wastewater treatment efficiency depends on the inoculum type, wastewater component composition and antibiotics content. With the use of granulated anaerobic sludge, during distillery wastewater treatment with norfloxacin content $10 \mathrm{mg} /$ $\mathrm{dm}^{3}$ and tetracycline $191 \mathrm{~cm} 3 / \mathrm{g}$ of wastewater the biogas yield reaches $254 \mathrm{~cm}^{3} / \mathrm{g}$ of wastewater, and methane content reaches $70 \%$.

Keywords: antibiotics, wastewater, biogas, microorganism association, sorbent

\section{INTRODUCTION}

In the process of antibiotics production by the chemical and microbiological methods, in spite of local sewage treatment, antibiotics content in sewage water reaches $10 \mathrm{mg} / \mathrm{dm}^{3}$ and higher. Such antibiotics content leads to the microorganisms destruction contained in anaerobic and aerobic active sludge, which are used for wastewater treatment. Also, antibiotics are contained in sewage and wastes from livestock and poultry farms. At the same time, their content varies from trace concentrations to tens of $\mathrm{mg} / \mathrm{dm}^{3}$. Antibiotics enter the natural environment, which adversely affects living organisms development With a low antibiotics quantities, bacteria resistant to this type of antibiotic develop, which leads to unpredictable consequences of their influence on the environment and mankind. Therefore, the development of utilization methods for wastewaters with low contents of antibiotics is an urgent task.

Technologies that are used for antibiotics removal from wastewater are based on different processes (Ahmed et al., 2015):

- Biotechnological (aerobic and anaerobic wastewater treatment, filtration through bioplato) (Hijosa-Valsero et al., 2011);

- $\quad$ physical (adsorption on sorbents and filters, destruction under the influence of physical factors - cavitation, ultrasound, flotation, etc.) (Serna-Galvis et al., 2016);

- chemical (oxidation and change to the form that does not have antimicrobial activity, precipitation, coagulation, flocculation, electrochemical oxidation) (Mehrjouei et al., 2014; Carlesi Jara et al., 2007).

The effectiveness of antibiotic utilization depends on the wastewater composition and impurities that are present in them (Polesel et al., 2016; (Quach-Cu et al., 2018).

The problem of biotechnological processing is a significant decrease in the microorganisms species numbers, as well as other hydrobionts of activated sludge after exposure to antibiotics, which, accordingly, reduces the quality of wastewater treatment, leads to sludge swelling and other technologica parameters deterioration (Ahmed et al., 2015). In such case, not all antibiotics groups can be utilized without the application of sorbents, which is especially characteristic of tetracyclines (Polesel et al., 2016)

Lefebvre et al. (2014) note that at low COD values $\left(220 \mathrm{mg} / \mathrm{dm}^{3}\right)$ under anaerobic conditions, the antibiotic production wastewater can be purified up to the required level during 24 hours. With an increase in COD up 10 times the use of biological methods only does not lead to the desired result. At such COD values, an increase in purification degree is possible with simultaneous use of ozonization, sorbents and biological treatment method.
Also, an increase in the wastewater purification degree from antibiotics is possible with the use of genetically modified microorganisms containing genes of antibiotic resistance. With the use of genetically modified activated sludge, the degree of wastewater treatment from norfloxacin is $80 \%$, which is $35 \%$ higher than standard sludge, with a purification rate of $45 \%$ (Ngumba, 2018).

In case of high antibiotics content 100-300 mg / dm 3 (doxycycline, gentamicin, penicillin, nitrofurantoin, rifampicin), the purification quality from other organic substances decreases due to a change in the active sludge species composition. Therefore, it is recommended to use sludge, with tolerant microorganism composition for this antibiotic type, and to apply other methods simultaneously with the biological method (Jendrzejewska et al., 2018)

Also, whith local wastewater treatment with a high antibiotic content ( $\beta$-lactams, tetracycline, macrolides, sulfonamides, quinolones), it is proposed to use genetically modified strains resistant to this type of antibiotic and that capable to utilize it (Cetecioglu et al., 2017).

Based on the volumes and concentration of sewage contaminants, the use of sorbents and filters is not cost-effective, since other pollutants will be sorbed in addition to antibiotics, which leads to rapid sorbent surface inactivation (Homem et al., 2011; Chen et al., 2010). Reverse osmosis technologies do not allow antibiotics utilization, but only concentrate them on the membrane (Wang et al., 2018). Also, large wastewater volumes and a low antibiotic content makes it difficult to use physical influence factors on molecules and their destruction.

Low content of antibiotics in wastewater does not allow the effective use of chemical methods. In this case, the introduction of additional substances leads to an increase in contamination degree and complicates the purification process. Such methods require further processing to remove the used reagents from the wastewater.

Currently the advanced oxidation process (AOPs) is considered perspective for antibiotics removal from wastewater. AOP is based on the generation of radicals $(\mathrm{eg}, \mathrm{OH} \bullet$ ), which have a greater reactivity and lesser selectivity compared to other oxidants such as chlorine and ozone. Radicals are obtained by using hydrogen peroxide or ozone in reaction with catalysts and / or ultraviolet radiation. Under the radicals influence, organic compounds oxidation to less toxic substances takes place, such substances are later used by microorganisms in the processes of destruction or utilization producing $\mathrm{CO}_{2}$ and $\mathrm{H}_{2} \mathrm{O}$. Examples of (AOPs) processes are ozonation, Fenton's reagent, electrochemical processes and semiconductor photocatalysis (Homem et al., 2011). To increase the degree of wastewater treatment from antibiotics, a various methods combinations is often used in practice (Michae et al., 2013).

The paper considers the biogas production during the various composition wastewater purification from antibiotics. 


\section{Formulation of the problem}

The works main goal is to determine the utilization conditions of antibiotics with the simultaneous biogas production during wastewater purification.

To achieve this goal it is necessary to solve the following tasks:

- to adapt anaerobic microorganisms associations to antibiotics (tetracycline and norfloxacin);

- investigate the biogas obtaining conditions during the wastewater treatment of various origin, containing different classes of antibiotics;

- determine the conditions to increase biogas yield and methane content in it.

\section{MATERIAL AND METHODS}

In this study the industrial wastewater of the Krasnoslobodsky distillery (Kyiv region, Ukraine) and wastewater from the pharmaceutical factory that produces antibiotics penicillin $\left(20 \mathrm{mg} / \mathrm{dm}^{3}\right)$ and cephalosporin $\left(5 \mathrm{mg} / \mathrm{dm}^{3}\right)$, as well as other medicines in Jinan (China) and municipal sewage of Jinan city (China) was used. Table. 1 shows the characteristic parameters of distillery wastewater.

Table 1 Parameters of distillery wastewater

\begin{tabular}{ll}
\hline Characteristic & Content, мг/дм \\
\hline Suspended substances & 38,0 \\
\hline $\mathrm{N}^{\mathbf{2}} \mathrm{NH}_{4}{ }^{+}$ & 14,0 \\
\hline $\mathrm{N}^{-N_{3}}{ }^{-}$ & 2,0 \\
\hline Phenols & 200, \\
\hline Sulfates & 900,0 \\
\hline Chlorides & 55,0 \\
\hline P-PO ${ }_{4}^{3-}$ & 20,0 \\
\hline Calcium & 1200,0 \\
\hline Chemical oxygen demand COD & 900,0 \\
\hline Biological oxygen demand BOD & 170,0 \\
\hline Synthetic surfactants SS & 0,8 \\
\hline
\end{tabular}

As an inoculum, anaerobic sludge from the anaerobic digestion of poultry waste with various types of plant raw materials was used (Department of Ecobiotechnology and Bioenergetics of the National Technical University of Ukraine "Kiev Polytechnic Institute named after Igor Sikorsky" (hereinafter referred to as the laboratory) and anaerobic sludge from the wastewater treatment plant of the pharmaceutical factory Jinan, China).

Adaptation of microorganisms association to tetracycline and norfloxacin antibiotics was conducted by using distillery plant wastewater under anaerobic conditions at a temperature of $37 \pm 1{ }^{\circ} \mathrm{C}$ by gradual increase in antibiotics content from $0.5 \mathrm{mg} / \mathrm{dm}^{3}$ to $10 \mathrm{mg} / \mathrm{dm}^{3}$ with steps of $0.5 \mathrm{mg} / \mathrm{dm}^{3}$. The period of adaptation to a certain antibiotic concentration was from 3 to 5 days. Adaptation period to a specific antibiotic concentration was determined by the biogas output. Determination of the chemical oxygen demand (COD) was carried out using standard method (Lurye, 1984). Determination of dry matter (DM), dry organic matter (DOM), ash content in wastewater - by the method (Ageyev et al., 1953). The mass of the substances was determined using CAUX220 scale (Japan) or OHAUS Scout PRO SPU-123 (China).

$\mathrm{pH}$ value was measured using an ionometer И-160 (RF) and a pH meter PHS-3E (China).

The granule surface was examined using a binocular microscope XSP-128B Ulab (China), ULAB XSP-139TR (China), Oxford X-Max 50 energy dispersive spectrometer (EDS)

Norfloxacin and tetracycline manufactured by Shanghai Macklin Biochemical Co., Ltd, China. Analysis of norfloxacin in wastewater was carried out by a modified procedure (Ahmed et al., 2015; Karlov, 2009) using spectrophotometers UV-5100 (China) and ULAB 102 (China), $\lambda=273 \mathrm{~nm}$.

Wastewater treatment and biogas production was conducted using $1.5 \mathrm{dm}^{3}$ reactors with a filling degree of 0.7 under anaerobic conditions at a temperature of $37 \pm 1{ }^{\circ} \mathrm{C}$ at a stirring rate of $60 \mathrm{rpm}$ in a continuous cultivation mode. Every day, $200 \mathrm{~cm}^{3}$ of purified water was replaced with wastewater. To maintain the temperature, the reactors were placed in a TS-80M (RF) thermostat. All reactors were connected to wet-type gasholders to collect biogas.

The biogas composition was determined by a standard method using a gas chromatograph Crystal 5000 («Khromatek», RF). Granulation of anaerobic sludge was performed using talc-based sorbent as a seed granule. (Advanced Materials Institute, Shandong Academy of Sciences, China).

Granulation was carried out in a thermoshaker LOIP LS-110 ("Labipleks» RF) in $50 \mathrm{~cm}^{3}$ flasks under anaerobic conditions at $37^{\circ} \mathrm{C}$, with stirring speed $60 \mathrm{rpm}$

\section{RESULTS AND DISCUSSION}

\section{Microorganisms adaptation}

As a result of microorganisms association adaptation to tetracycline antibiotics (CAS number 64-75-5), which belong to substituted hydroxyamines and in the basis of chemical structure they contain the octahironaphthacene core (fig. 1b), and norfoxacin (CAS number 70458-96-7), which belongs to fluoroquinolones (fig. 1a), viable associations were obtained that under anaerobic conditions produced biogas.<smiles>CCn1cc(C(=O)O)c(=O)c2cc(F)c(N3CCNCC3)cc21</smiles>

Figure 1 General formula of tetracycline (b) and norfloxacin (a)

Adaptation of microorganisms association to tetracycline and norfloxacin was carried out using anaerobic laboratory sludge. The wastewater of the distillery was used as model sewage. Figures 2 and 3 show the biogas output in the process of wastewater treatment containing different antibiotics quantities - norfloxacin (fig. 2) and tetracycline (fig. 3) without preliminary adaptation of microorganisms association.

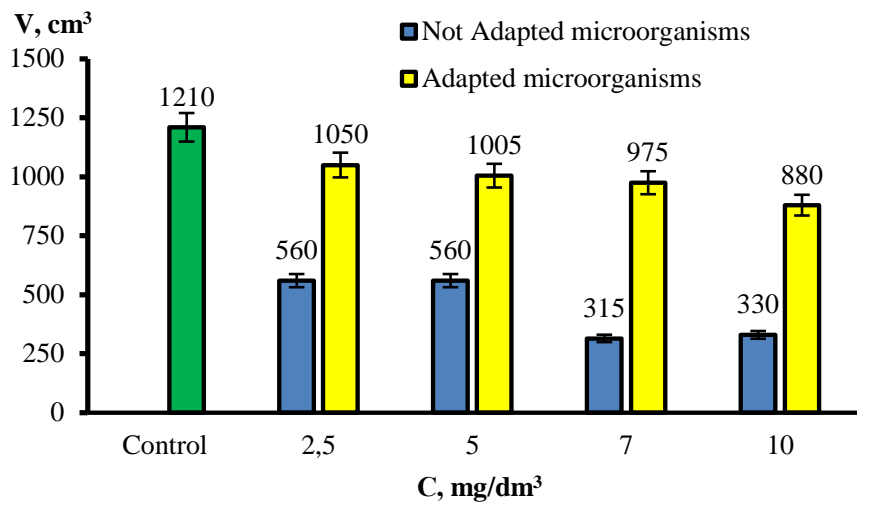

Figure 2 The biogas yield $(\mathrm{V})$ in the process of wastewater treatment at various quantities of norfloxacin without and with the preliminary adaptation of microorganisms association

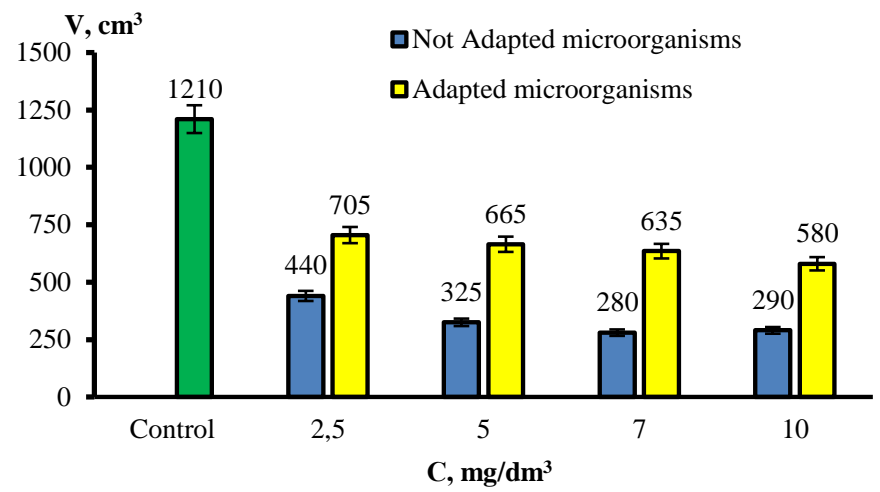

Figure 3 The biogas yield $(\mathrm{V})$ in the process of wastewater treatment at various quantities of tetracycline without and with the preliminary adaptation of the association of microorganisms

Biogas yield without prior adaptation of microorganisms association at norfloxacin content of 2.5 and $5 \mathrm{mg} / \mathrm{dm}^{3}$ is half that of control (wastewater without antibiotics), and with content of 7 and $10 \mathrm{mg} / \mathrm{dm}^{3} 4$ times less. At the same time, there is no methane in the biogas of the last two samples. Thus, the content of norfloxacin above $5 \mathrm{mg} / \mathrm{dm}^{3}$ in wastewater leads to the cessation of methanogens vital activity. Biogas in that case, mainly, consists of carbon dioxide, i.e. in the association microorganisms-destructors tolerant to the antibiotic still function, this is confirmed by a decrease in the $\mathrm{pH}$ from 7.15 to 6.2

During the sewage treatment process with different content of tetracycline, by the association that was not adapted methane is released only when the tetracycline content in the waste water is $2.5 \mathrm{mg} / \mathrm{dm}^{3}$. At the same time, the biogas yield is 2.75 times less in comparison to control sample. As with norfloxacin, when the antibiotic content increases, the duration of biogas output decreases. With content of $10 \mathrm{mg} / \mathrm{dm}^{3}$, biogas formation occurs during the first 2-3 days.

During the adaptation of microorganisms association, the biogas yield stabilizes and reaches 300 and $600 \mathrm{~cm}^{3} /$ day during wastewater treatment containing tetracycline and norfloxacin respectively, regardless of their content in wastewater. Methane content in biogas is $60 \pm 1 \%$ for wastewater with 
tetracycline and $64 \pm 1 \%$ for norfloxacin and decreases with increase in antibiotics content.

Pharmaceutical plant sewage water contains besides penicillin and cephalosporin antibiotics other organic substances, which can adversely affect the microorganisms development. To adapt the microorganisms association to different classes of antibiotics and other organic substances, and to provide it with ability to utilize them, sludge from the anaerobic reactor of the pharmaceutical plant was used, whose microorganisms are adapted to penicillin and cephalosporin, and anaerobic sludge from a laboratory plant adapted to tetracycline and norfloxacin. The adaptation of the latter to organic substances that are contained in the pharmaceutical plant sewage water was carried out by gradual increase in the content of pharmaceutical wastewater in municipal wastewater.

The sludge adaptation from the pharmaceutical plant to norfloxacin and tetracycline was carried out using wastewater from a pharmaceutical plant and municipal sewage, increasing the content of antibiotics in steps of $1 \mathrm{mg} / \mathrm{dm}^{3}$ The antibiotic content was increased every 2 days.

The results of biogas yield in the microorganism associations adaptation process to antibiotics in sewage are shown in fig. 4,5 . In samples 1 and 2, which contained sludge from a laboratory plant, at the constant frequency antibiotic and wastewater from the pharmaceutical plant were added replacing $240 \mathrm{~cm}^{3}$ of municipal wastewater.

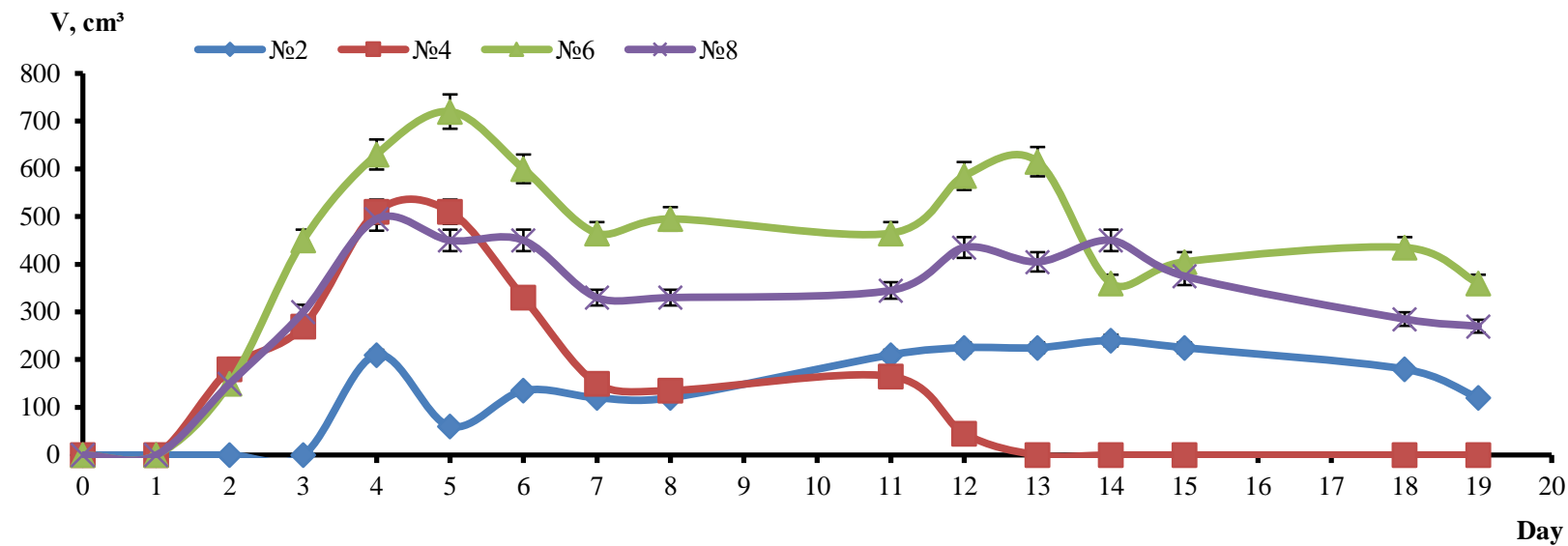

Figure 4 Biogas yield (V) during microorganisms association adaptation to tetracycline (№2,4,6) and pharmaceutical plant sewage water (№.2). Samples №4 - pharmaceutical plant sludge + pharmaceutical plant wastewater + tetracycline, №6 - pharmaceutical plant sludge + municipal waste water + tetracycline, №8 - control - pharmaceutical plant sludge + municipal wastewater, No. 2 - laboratory plant sludge + pharmaceutical plant wastewater + tetracycline

As can be seen from fig. 4, the greatest biogas yield is characteristic for usage of anaerobic sludge from a pharmaceutical plant and municipal wastewater (sample №6). The presence of tetracycline was an activator for microorganisms that are part of anaerobic sludge. The biogas yield in comparison with control sample grew $34 \%$. At the same time, the same sludge in the pharmaceutical plant sewage water with an increase in tetracycline content above $5 \mathrm{mg} / \mathrm{dm}^{3}$ shows no signs of vital activity. Therefore the presence of different antibiotic classes and other organic substances leads to inhibition of microorganisms development.

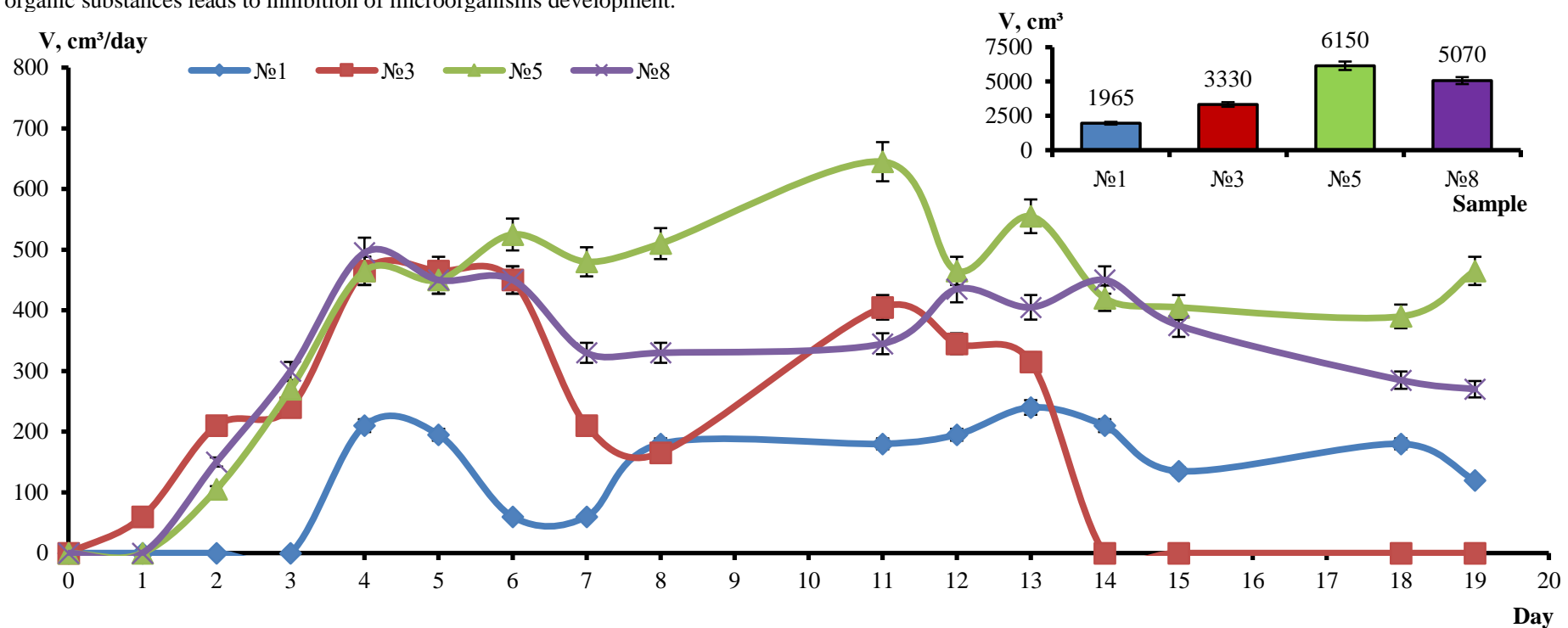

Figure 5 Biogas yield (V) during microorganism associations adaptation to norfloxacin № 1,3,5 and pharmaceutical plant wastewater № 1. Samples: №3 pharmaceutical plant sludge + pharmaceutical plant sewage water + tetracycline, №5 - pharmaceutical plant sludge + municipal waste water + tetracycline, №8 control - pharmaceutical plant sludge + municipal wastewater, №1 - laboratory plant sludge + pharmaceutical plant sewage water+ tetracycline

As can be seen from fig. 5 , the biogas yield in sample №5 exceeds by $22 \%$ the biogas yield in control sample. The biogas yield during the sludge adaptation to the pharmaceutical plant sewage water is only $34 \%$ of the maximum yield. At the same time, a stop in vital activity of pharmaceutical plant anaerobic sludge can be observed at a norfloxacin content exceeding $6 \mathrm{mg} / \mathrm{dm}^{3}$.

Based on the results obtained, we can state that:

- the microorganisms association, which is initially tolerant to tetracycline or norfloxacin, is capable of both adapting to the pharmaceutical plant sewage water, which contains other antibiotics - penicillin and cephalosporin, and to generate methane;
Adaptation of the tetracycline tolerant laboratory sludge to the sewage water of the pharmaceutical plant, which contains two other antibiotics classes (sample №2), is characterized by a prolonged lag-phase and a low biogas yield, $27 \%$ of the maximum yield, which is typical for sample No. 6 .

The same relation is also characteristic for microorganism associations adapting to norfloxacin (fig. 5) 
Pharmaceutical plant wastewater treatment with different classes of antibiotics for biogas production

To increase the degree of wastewater treatment and biogas yield, it is necessary to increase the microorganism content in the reactor. One way to increase microorganism content is their granulation. Sorbents based on talc and silica ge with hydrogel alginates were used as granulation centers. Sorbents based on hydrogel alginates № 1 and № 2 were ruined in the distillery and pharmaceutical plant sewage water on day 6 and 2, respectively.

In the pharmaceutical factory wastewater, when using sorbent №3 based on talc and selected microorganisms association from the pharmaceutical plant, toleran to the tetracycline and norfloxacin content of $4 \mathrm{mg} / \mathrm{dm}^{3}$, the formed biofilm peels off the sorbent granule.

When using microorganism associations obtained in laboratory reactor tolerant to the same content of tetracycline and norfoxacin, the formed film on the sorbent did not exfoliate and was stable.

Fig. 6 shows the biogas yield and methane content in it during pharmaceutical plant wastewater treatment containing $10 \mathrm{mg} / \mathrm{dm}^{3}$ of norfloxacin or tetracycline and a mixture of $10 \mathrm{mg} / \mathrm{dm}^{3}$ of both using free-floating and granulated anaerobic sludge.

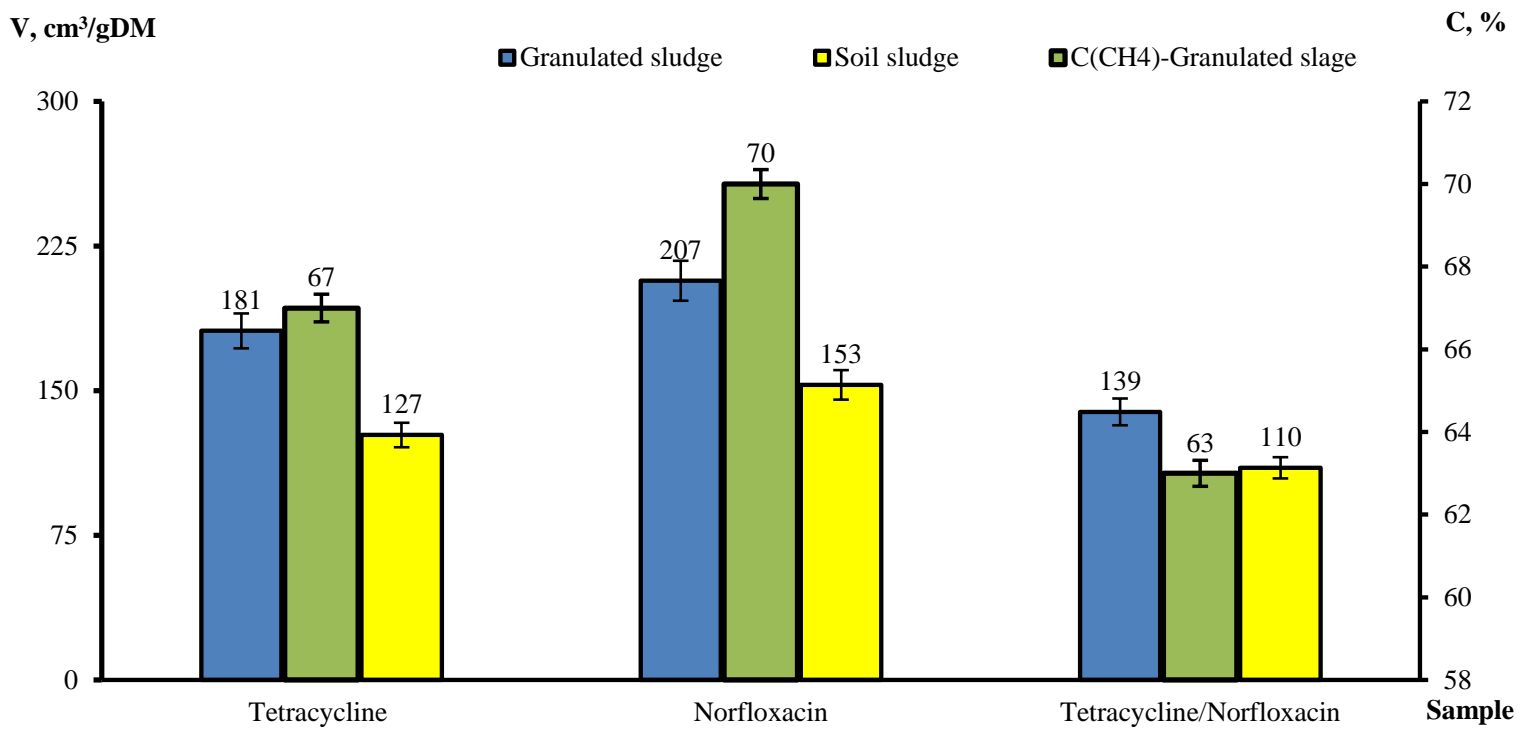

Figure 6 Biogas yield (V) and methane content $(\mathrm{C})$ during distillery plant wastewater treatment with antibiotics content of norfloxacin and tetracycline $10 \mathrm{mg} / \mathrm{dm}^{3}$ and a mixture of $10 \mathrm{mg} / \mathrm{dm}^{3}$ each using free-floating and granulated anaerobic sludge

Based on the data obtained (fig. 6), the biogas yield is increased by $26 \%$ using granulated sludge in the presence of norfloxacin and $29 \%$ in the presence of tetracycline. When using a mixture of tested antibiotics - by $20 \%$. The biogas yield on average per day for 20 days is $191 \mathrm{~cm}^{3} / \mathrm{g}$ for a sample with tetracycline or $254 \mathrm{~cm}^{3} / \mathrm{g}$ for a sample with norfloxacin. At the same time, methane content in biogas reaches $70 \pm 2 \%$ in the presence of norfloxacin and $67 \pm 2 \%$ in the presence of tetracycline, and in the presence of both antibiotics, the conten reaches $63 \%$.

Disposal of antibiotic can occur both as a result of its degradation, and due to adsorption on the granule surface. At the same time, adsorption on the granule surface is a fast process and can be accompanied by a desorption process Antibiotic destruction is associated with its transfer to the cell or the exoenzymes biosynthesis, which results in antibiotic destruction and formation of non-toxic substances, this process is longer than absorption.

The degree of wastewater purification from norfloxacin at its content of $10 \mathrm{mg} /$ $\mathrm{dm}^{3}$ with granulated anaerobic sludge tolerant to norfloxacin, with a 2 hour water retention in the reactor is $56 \%$, at a 24 hours retention $72 \%$. Increase the purification degree from norfloxacin with prolonged retention time in the reactor leads to the destruction of the antibiotic. Therefore to conduct the process of norfloxacin destruction by the microorganisms association tolerant to it, the required time of wastewater retention in the reactor is 24 hours.

Fig. 7 and 8 show the degree of distillery wastewater purification with the tetracycline or norfloxacin content determined through COD, depending on their content, adapted to these antibiotics, free-floating and granulated sludge when water is retained in the reactor for 24 hours.

For a sample with norfloxacin, the allowable range of antibiotic content, at which wastewater treatment reaches required level, by free-floating anaerobic active sludge is $5 \mathrm{mg} / \mathrm{dm}^{3}$. At a higher content, the purification rate (determined by COD) decreases and is $58 \%$ at $10 \mathrm{mg} / \mathrm{dm}^{3}$. This can be explained by a decrease in the number of microorganism species in anaerobic sludge that are involved in the pollutants utilization under antibiotic influence. When granular sludge is used, the purification rate is $71 \pm 2 \%$ with a content of norfloxacin $10 \mathrm{mg} / \mathrm{dm}^{3}$ and increases with a decrease in the antibiotic content up to $79 \pm 2 \%$. In this case $72 \pm 1 \%$ of norfloxacin is removed from wastewater. 


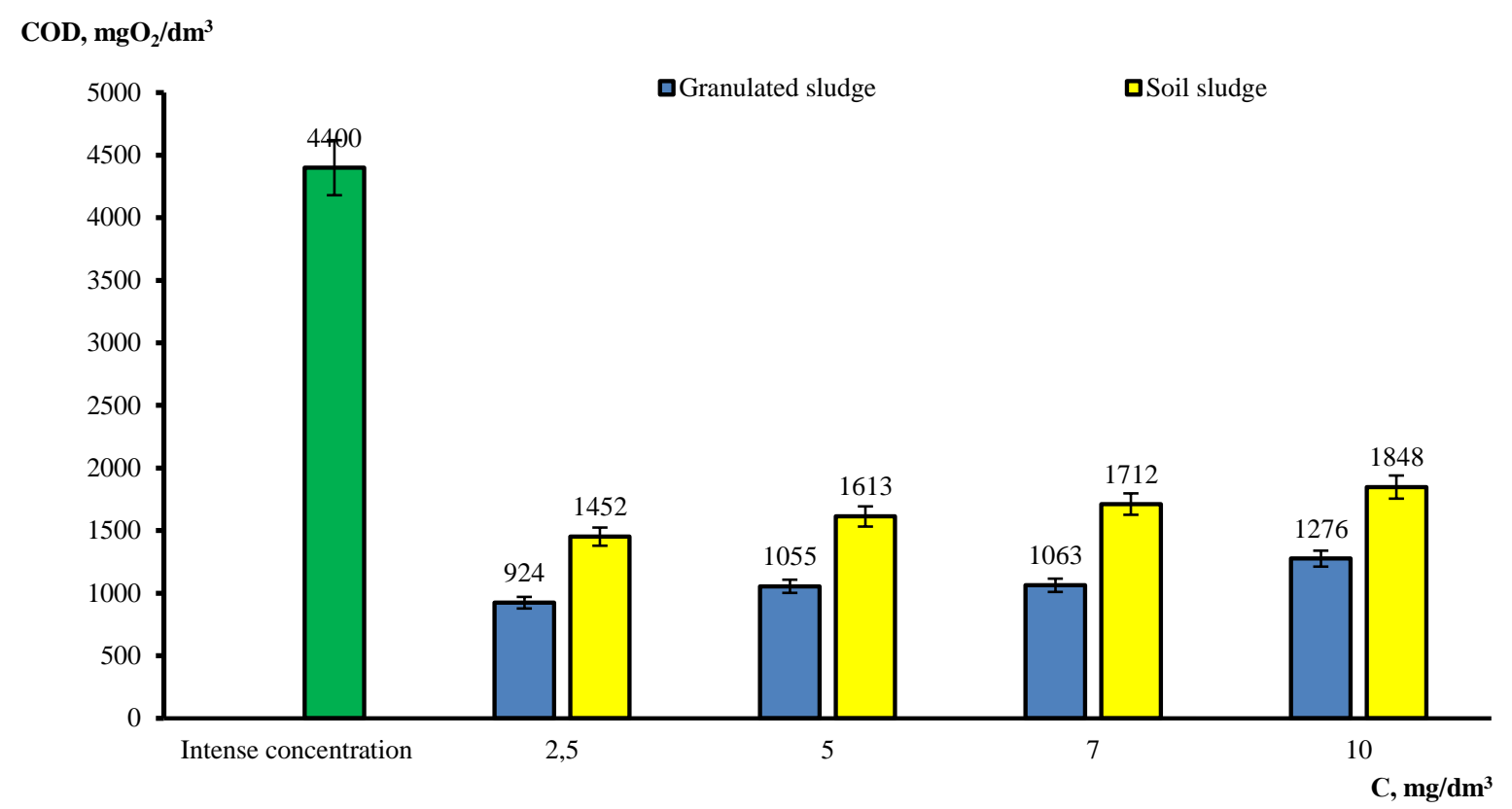

Figure 7 Purification degree of distillery sewage in relation to the norfloxacin content (C) using free-floating and granulated anaerobic sludge

\section{$\mathrm{COD}, \mathrm{mgO}_{2} / \mathrm{dm}^{3}$}

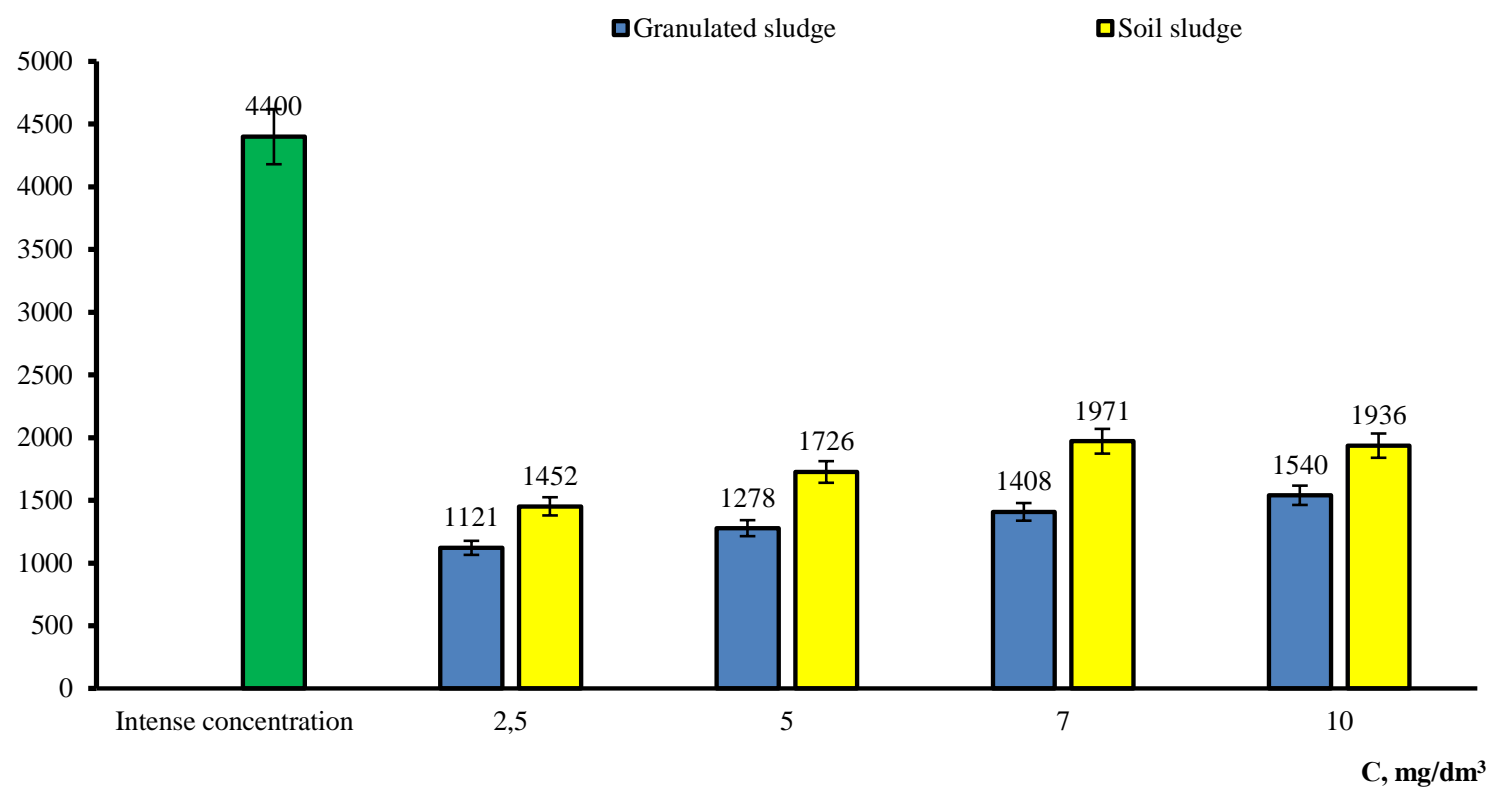

Figure 8 Purification degree of distillery sewage in relation to the tetracycline content (C) using free-floating and granulated anaerobic sludge Figure 9 shows the relation of pharmaceutical plant sewage treatment degree, The relation shown in fig. 8 is characterized by a decrease in the tetracycline content, at which wastewater is purified in anaerobic conditions (by COD) $67 \pm$ $2 \%$ by free-floating anaerobic skage at antibiotic content of $2.5 \mathrm{mg} / \mathrm{dm}^{3}$ and 56 $\pm 1 \%$ at $10 \mathrm{mg} / \mathrm{dm}^{3}$. The use of granulated anaerobic sludge allows to increase the purification rate at an antibiotic content of $10 \mathrm{mg} / \mathrm{dm}^{3}$ up to $65 \pm 2 \%$. antibiotics and organic substances - inhibitors of microorganisms vital activity. 


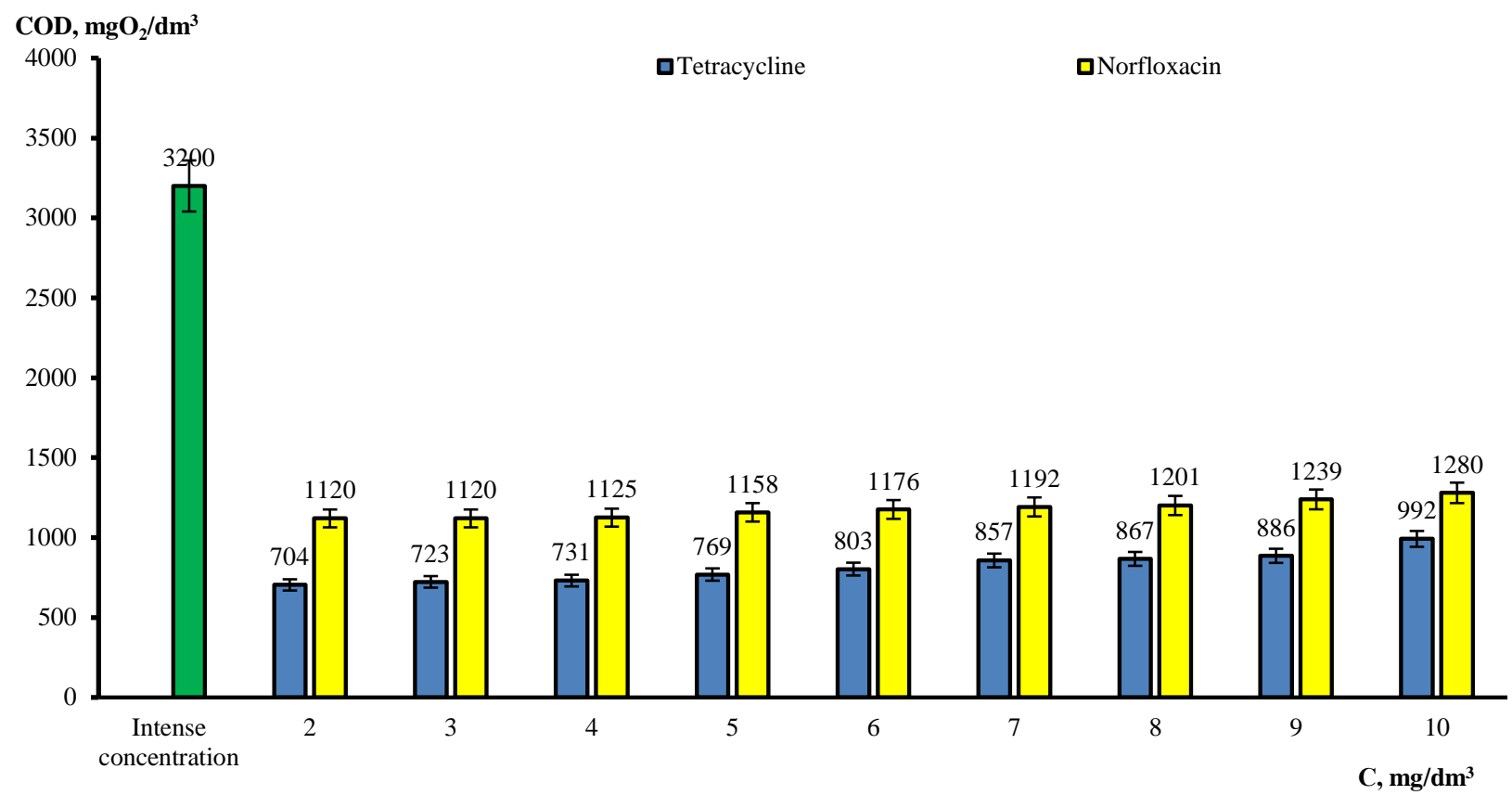

Figure 9 Pharmaceutical plant wastewater treatment degree containing norfloxacin and tetracycline, in relation to their content (C)

As can be seen with anaerobic sludge, first adapted to tetracycline or norfloxacin purification does not depend on the concentration of antibiotics to $10 \mathrm{mg} / \mathrm{dm}^{3}$. Under such conditions, the purification rate by COD is $69-78 \%$ with norfloxacin and $60-65 \%$ with tetracycline.

\section{CONCLUSIONS}

1. Adaptation of anaerobic sludge, obtained from poultry droppings and cellulose-containing agricultural waste fermentation, to tetracycline and norfloxacin makes it possible to purify wastewater from antibiotics with simultaneous biogas production. The biogas yield during the distillery wastewater purification is $191 \mathrm{~cm}^{3} / \mathrm{g}$ for norfloxacin and $254 \mathrm{~cm}^{3} / \mathrm{g}$ for tetracycline with a methane content reaching up to $70 \%$ and $67 \%$, respectively.

2. Under anaerobic conditions, the degree of distillery sewage treatment (by COD) by granulated sludge is $80 \%$ for water containing norfloxacin and $67 \%$ for water containing tetracycline and decreases with increase of antibiotics contents. 3. The degree of pharmaceutical plant wastewater treatment containing other classes of antibiotics starts from $60 \%$ and reaches higher for tetracycline and $65 \%$ and higher for norfloxacin.

\section{REFERENCES}

Ageyev. L. M., Korolkov, S. I. (1953). Chemical and technical control and accounting of hydrolysis and sulfite-alcohol production. Moscow: Goslesbumizdat. ISBN 978-5-4458-4293-4. (in Russ.)

Ahmed, M.B., Zhou, J. L., Ngo, H. H., Guo, W. (2015). Adsorptive removal of antibiotics from water and wastewater: Progress and challenges. Science of the Total Environment, 532, 112-126. https://doi.org/10.1016/j.scitotenv.2015.05.130

Carlesi Jara, C., Fino, D., Specchia, V., Saracco, G., Spinelli, P. (2007) Electrochemical removal of antibiotics from wastewaters. Applied Catalysis B Environmental, 70, 479-487. https://doi.org/10.1016/j.apcatb.2005.11.035 Cetecioglu, Z., Atasoy, M. (2018). Biodegradation and inhibitory effects of antibiotics on biological wastewater treatment systems. Chapter 2. Toxicity and Biodegradation Testing, 29-55. https://doi.org/10.1007/978-1-4939-7425-2_2

Chen, W.-R., Huang, C.-H. (2010). Adsorption and transformation of tetracycline antibiotics with aluminium oxide. Chemosphere, 79, 779-785. https://doi.org/10.1016/j.chemosphere.2010.03.020

Hijosa-Valsero, M., Fink, G., Schlüsener, M. P., Sidrach-Cardona, R., MartínVillacorta, J., Ternes, Th., Bécares, E. (2011). Removal of antibiotics from urban wastewater by constructed wetland optimization. Chemosphere, 83, 713-719. https://doi.org/10.1016/j.chemosphere.2011.02.004

Homem, V., Santos, L. (2011). Degradation and removal methods of antibiotics from aqueous matrices. A review. Science of the Total Environment, 92 (10), 2304-2347. https://doi.org/10.1016/j.jenvman.2011.05.023

Jendrzejewska, N., Karwowska, E. (2018). The influence of antibiotics on wastewater treatment processes and the development of antibiotic resistan bacteria. Water science and technology, 11 (77), 2320-2326. https://doi.org/10.2166/wst.2018.153
Karlov. P.M. (2009). Fluoroquinolone analysis in substances, dosage forms and biofluids. Kurskiy nauchno-prakticheskiy vesnik «Chelovek i ego zdorovye», 1, 143-147. (in Russ.)

Lefebvre, O., Shi, X., Wu, C. H., Ng, H. Y. (2014). Biological treatment of pharmaceutical wastewater from the antibiotics industry. Water Sci Technol, 69 (4), 855-861. https://doi.org/10.2166/wst.2013.729

Lurye Yu. Yu. (1984). Analytical chemistry of industrial wastewater. Moscow: Khimiia, 448 p. (in Russ.)

Mehrjouei, M., Müller, S., Möller, D. (2014). Energy consumption of three different advanced oxidation methods for water treatment: a cost-effectiveness study. J. Cleaner $\quad$ Prod, $\quad 65, \quad 178-183$ https://doi.org/10.1016/j.jclepro.2013.07.036

Michael, I., Rizzo, L., McArdell, C.S., Manaia, C.M., Merlin, C., Schwartz, T., Dagot, C., Fatta-Kassinos, D. (2013). Urban wastewater treatment plants as hotspots for the release of antibiotics in the environment: A review. Water Research, 47 (3), 957-995. https://doi.org/10.1016/j.watres.2012.11.027

Ngumba, E., Gachanja, A., Tuhkanen ,T. (2016). Occurrence of selected antibiotics and antiretroviral drugs in Nairobi River Basin, Kenya. Science of the Total Environment, 539, 206213. https://doi.org/10.1016/j.scitotenv.2015.08.139

Polesel, F., Andersen, H.R., Trapp, S., Plósz, B.G. (2016). Removal of Antibiotics in Biological Wastewater Treatment Systems-A Critical Assessment Using the Activated Sludge Modeling Framework for Xenobiotics (ASM-X) Environmental Science \& Technology, 50 (19), 10316-10334. https://doi.org/10.1021/acs.est.6b01899

Quach-Cu, J., Herrera-Lynch, B., Marciniak, Ch., Adams, S., Simmerman, A Reinke, R. A. (2018). The Effect of Primary, Secondary, and Tertiary Wastewater Treatment Processes on Antibiotic Resistance Gene (ARG) Concentrations in Solid and Dissolved Wastewater Fractions. Water MDPI, 10 (1), 37, 1-18. https://doi.org/10.3390/w10010037

Serna-Galvis, E. A., Silva-Agredo, J., Giraldo-Aguirre, A. L., Flórez-Acosta, O. A., Torres-Palma, R. A. (2016). High frequency ultrasound as a selective advanced oxidation process toremove penicillinic antibiotics and eliminate its antimicrobial activityfrom water. Ultrasonics Sonochemistry, 31, 276-283. https://doi.org/10.1016/j.ultsonch.2016.01.007

Wang, Y., Wang, X., Li, M., Dong, J., Sun, C., Chen, G. (2018). Removal of Pharmaceutical and Personal Care Products (PPCPs) from Municipal Waste Water with Integrated Membrane Systems, MBR-RO/NF. International Journal of Environmental Research and Public Health, 15 (2), 269, 1-11. https://doi.org/10.3390/ijerph15020269 